\title{
Modulation of protease activity to enhance the recovery of recombinant nucleocapsid protein of Nipah virus
}

\begin{abstract}
The nucleocapsid (N) protein of Nipah virus (NiV) expressed in Escherichia coli (E. coli) is antigenic and immunogenic. A method to enhance the recovery of recombinant $\mathrm{N}$ protein of $\mathrm{NiV}$ produced in E. coli is described. A bioinformatics tool, PeptideCutter was used to identify potential protease and cleavage sites from the amino acid sequences deduced from the published DNA sequence of the $\mathrm{N}$ protein of NiV. The size of degraded protein was estimated by using the Western blot and PeptideCutter analyse. The identified proteases were serine proteases, hence, a range of serine protease inhibitors were tested to improve the recovery of the $\mathrm{N}$ protein. The relative amount of $\mathrm{N}$ protein of $\mathrm{NiV}$ was 2 -fold higher with the addition of PMSF, compared to the control sample (without any protease inhibitor supplementation).
\end{abstract}

Keyword: Endogenous protease, Protease inhibitor, Nucleocapsid protein, Nipah virus, Escherichia coli 